Right at the start:

a research and development agenda for teacher induction

\begin{abstract}
Recent developments in teacher induction in both England and Scotland are bringing long overdue improvements, but there is a range of issues in need of further exploration if policy is to be developed. Current evaluations have begun to reveal the absence of some important conceptual aspects of induction in the somewhat hasty implementation. Some of these have been well rehearsed in the literature over the years but have generally failed to make any impact hitherto in induction policy. This paper picks up and discusses some of the conceptual tensions and weaknesses that have, or are likely to, become practical issues of quality, in both Scottish and English induction policies. These include the use of competence-based descriptions, the non-formal dimension of learning to teach, open narrative and focused approaches to classroom observation and feedback, individualism and a pupil perspective. The array of concepts is organised into a constructive, topical agenda which, it is argued, bring a much needed formative dimension to research and development in this crucial area of professional learning.
\end{abstract}

Jim McNally and Iddo Oberski

Jim McNally

Institute of Education

University of Stirling

Stirling

Scotland

FK9 4LA

Email: j.g.monally@stir.ac.uk 


\section{Right at the start: an agenda for research and development in teacher induction}

\section{Introduction}

The induction of newly qualified teachers has finally come to the centre of policy making in both England and Scotland, after decades of marginalisation. Although the statutory framework for England (DfEE, 1999) has been duly criticised for its focus on administrative arrangements (Tickle, 2000b; ATL, 2000), the early evaluative evidence suggests that many more new teachers are now receiving some form of direct support (Harrison, 2001; Bubb et al, 2001). In Scotland, the traditional two-year 'probation' period has steadily deteriorated into a fragmented experience of supply teaching for many new teachers, a situation described by the Commission of Inquiry as 'little short of scandalous' (McCrone Report, 2000, p.7). The Scottish Executive Education Department (SEED) and the General Teaching Council for Scotland (GTCS) jointly set up a project to develop induction (McNally, 2000), the results of this project have now been published (McNally 2001) and recommendations for the induction of newly qualified teachers in Scotland are to be implemented from August 2002. The policy makers in Scotland have accepted the reality of the crisis of fragmented induction and now "guarantee that all newly qualified teachers will have access to a training post for one school session immediately after qualification" (Scottish Executive 2002, p8). This is a clear improvement on the current situation, even though the practicalities of implementing this decision may prove a big challenge. For example, how would this new guarantee accommodate new teachers in subjects for which there are too many teachers? There is, therefore, a new set of practical issues for consideration, which will fall under the remit of the Induction Implementation Group that is to be established.

Despite the immediate positive consequences for new teachers of statutory induction in both England and in Scotland, a range of fundamental weaknesses in the induction process is still apparent. This is not surprising, given the absence of a theoretical basis to the proposed changes and the haste with which they were formulated and implemented. However, with teacher induction firmly on the current policy agenda, the time is right to reexamine teacher induction and give a new impetus to research in this area. It has after all been recommended in the report of the National Committee of Inquiry into Higher Education (Sutherland Report (Report 10, 1997), that induction be pursued in partnership with Higher Education. Although that covers a variety of possible roles (McNally, 2002), research is the most obvious area in which a distinctive contribution can be made in that partnership. For this paper, therefore, a basic premise is that there are some fundamental theoretical and conceptual aspects of induction missing from current policy formulation that may be exposed in implementation. The failure to take these into account in the policy formation process may in the long term be detrimental to the professional development of teachers. These issues need further exploration if effective policy in this area is to be further developed to support new teachers. 
Of course, certain aspects of induction have been well rehearsed in the literature over the years, but have generally failed to make an impact in policy. In Scotland, much of the writing has tended toward criticism (e.g. Stronach et al, 1994; Humes, 2001), without proposing an alternative way forward, although some commissioned reports do have indirect influence (e.g. Brown et al, 1993; Draper et al, 1997). In England, the emergent body of evaluative studies (e.g. Bubb et al, 2001; Harrison, 2001; Simco, 1999) is corroborating, but also refining and extending, the range of directly relevant questions in need of attention. These include the role of the induction tutor, the use and misuse of protected time, assessment and development documentation. However, the emphasis appears to be on evaluation of an implementation to the exclusion of more fundamental research. The exception is perhaps Tickle (2000a, 2000b), who has drawn attention to the turbulent nature of the student-to-teacher transition, but who has also been constructive in developing an induction curriculum.

This paper discusses some of the conceptual tensions and weaknesses that have, or are likely to become, practical issues of quality in induction policies, within a Scottish context but with possibly wider application. In the UK at least, we have a moment of potential synergy between theory and emerging 'real' issues, an opportunity for research to be actively developmental in reaching into practice through policy fomulation, in a way which engages with a more public understanding (Barnett, 2000). These conceptual issues are therefore presented as an agenda for the research and development of induction. The scope of this task does not allow for a full review of the literature for each of the agenda 'items', even if that were feasible, though it has drawn on findings from previous work with colleagues on the experiential learning of student teachers and probationers (McNally et al, 1994,1997). The intention is to convey the essence of each issue as a salient area for further understanding and exploration.

\section{The users of specific competence statements}

Although there are strong arguments against competences ${ }^{i}$ as a valid or helpful conceptual basis for defining standards or guiding development (Barnett, 1994; Stronach et al, 1994; Humes, 2001), yet there appears to be a degree of practitioner support for them. This apparent paradox needs to be explained. We need to know who actually uses competences and in what way. It may be that the users find statements of specific competence of assistance in discharging the support and assessment tasks their responsibilities require of them. Do they deploy them in a limited but useful way without over-reliance or misuse, or is it mere compliant rhetoric? Do competences have implications for pedagogy in the process of learning to teach as well as for making decisions on the product of this process?

Although this apparent practitioner support lends weight to a competencebased standard for full registration (SFR) in Scotland (SEED, 2001), the requirement to express the SFR in terms of competences has a political origin. The actual form of the competence-based SFR was determined at the outset by remit to build on the existing competences for initial teacher 
education (ITE). It was thus in the straitjacket of the ITE standard required by the Quality Assurance Agency for Higher Education (QAA, 2000), which in turn studiously included all of the preceding competences from the Guidelines (SOEID, 1998a). Of course the ITE standard was put together by a broadlybased group which included representatives from teacher education institutions (TEI), some of whom supported the competence-based approach, some of whom had reservations of varying gravity. Such variations do not tend to survive the writing and editing of official reports, and the ITE standard was not an exception. With the addition of a consultation exercise, it therefore has the appearance of being produced from a consensus of educationists.

The aim in Scotland was to have a 'seamless garment'ii of professional development. However, it is not apparent that this garment was indeed made out of one piece of fabric, or that the different pieces were woven, rather than sewn together. In other words, it is not clear on what understanding(s) of teacher development it was based. In fact, there seems to have been no conceptual basis or rationale, research-based or otherwise, underpinning these developments. This is a laudable aspiration, but it should surely have been accompanied by a professional debate, a philosophical examination or a review of literature - or all three. The standards published so far - the standard for headship (Scottish Office, 1998b), the ITE standard (QAA, 2000) and the SFR or induction standard (SEED, 2001) - were all developed separately and differently (and this also applies to the current development of the standard for chartered teacher in Scotland). Yet they are all characterised by lists of competences, suggesting the hidden hand of the 'new managerialism' (Fairley and Paterson, 1995; Hartley, 1997). It is unfortunate that we do not now have the variety of models of teacher performance and development at different stages which this diversity of approach might have yielded, had each been allowed to run with greater independence, rather than the present appearance of a natural coherence.

The Induction Report, 'The induction of new teachers in Scotland' (McNally, 2001) has acknowledged the existence of 'holistic' competence. Headteachers, in project interviews, expressed their expectations of new teachers in these terms, for example of having the respect of classes taught, being valued by colleagues and contributing to aspects of whole school life. In the induction standard itself, these have been expressed as holistic indicators, but it is possible that this may actually be a source of confusion rather than illumination to those who are used to, and who may well prefer, a list of more specific competences. Nevertheless, the notion of holistic competence has a better grounding in the data than atomistic competence statements. It would appear to belong to the natural working discourse of practitioners in a way that atomised statements do not. Of course, the nature of that discourse may have begun to include the use of specific competences. It is conceivable that study of this discourse may reveal genuine tensions between different ways of discussing teaching or, possibly, different learning styles of new teachers. If so, then these tensions and differences need to be understood and included in statements of induction policy. To do this, we need to study the users. 


\section{An Induction curriculum}

There is a certain managerial logic in thinking that whatever competencebased standard for induction is in place will automatically govern the induction experiences of new teachers. If the first issue on our agenda were to be resolved to indicate that such a curriculum model was indeed operated by users to the satisfaction of all, then an induction curriculum would cease to be an issue, in terms of content at least. The rather extensive list of specific competences in the SFR has been viewed as somewhat ambitious by some, but the inherent scope for user interpretation in statements of competence tends to counter this objection. The point is that these competences are not acquired in a simplistic, linear kind of way. Few are convinced that teachers learn like this. The complexity of teaching and of learning to teach cannot be so easily prescribed. Nor does there appear to be any simple continuity of learning from student teaching into beginning as a new teacher (Tickle, 2000a). The Career Entry Profile, used in England, suggests that there is bureaucratic pressure to impose such continuity but so far its value remains in doubt, though there has been a positive effect on teacher development of regular observation and review meetings (Harrison, 2001). These take place within the school and it does appear to confirm that support for the individual new teacher from colleagues in school offers a most important feature of any induction curriculum.

It is probable that a strong component of this support is of a social and emotional nature and helps new teachers to feel that they are accepted within their new community (McNally et al, 1994; Oberski et al, 1999). What is not clear is the extent to which support is individualised. What kind of learning needs arise, who raises them and how are they handled? To what extent are they different across new teachers? According to Harrison (2001), 'where professional support occurs the provision appears to be largely for those with particular needs or inadequacies', suggesting that a deficit and not a progressional curriculum model is driving induction practice.

The importance of individualised support was, however, seen to be a key component of the proposed Scottish induction framework (McNally, 2001), reflected in the key role of the school induction tutor, similar to the English role. What also gathered a momentum of consensus as the Scottish project developed was the idea of a common induction programme (which includes the right to individual support). This common programme came largely from a background of varied induction initiatives by the local authorities, supported by central funding. The education officers from the local authorities, in particular, felt that needless duplication of effort and output might be avoided if a common central programme could be devised. Although the school was seen to be the crucial arena of development and support, there was the question of local co-ordination and the perception that the local authority was better placed to either deliver or organise certain topics e.g. the legal context of teaching, local policy emphasis and procedures.

Bringing new teachers together on a local basis has obvious social and networking benefits, and widens the range of peer contacts as a source of 
support, generally accepted as fundamentally important ${ }^{\mathrm{iii}}$. A problem arises, however, when a new teacher has to leave timetabled classes in order to attend meetings. This compounds the large and growing concern about the quality of cover and the aftermath for teachers and schools of poor quality cover. In one school, a large city secondary, the headteacher revealed that, over a one month spell, classes had not been taught by their normal teachers, because of attending meetings called outside school, in over 5000 timetabled periods $^{\text {iv }}$. The staff had consequently agreed on a moratorium on attending any meetings that took them from classes. The daily timetabled nature of the teachers' work does present a difficulty for traditional meetings for communal development but there is surely a strong case for avoiding a collision between teaching continuity and structured induction for new teachers. There are a number of solutions: lighter teaching timetables, freeing up the same (half) days for all new teachers, twilight or weekend attendance. Perhaps the best prospect of delivering a common programme will prove to be through communications technology ${ }^{\mathrm{v}}$ through, for example, an online set of modules, collaboratively produced, complemented by a small number of face to face gatherings.

\section{Classroom observation and feedback}

As indicated above, support for new teachers appears to have greatly improved in England, notably through regular observations and review meetings. There can be little doubt that the opportunity to discuss one's own teaching with colleagues who have observed it is welcome, given certain characteristics, for example trust, experience and personal rapport, might be added. While natural mentoring (McNally, 1994) may well occur through a variety of different individuals, there is a strong case for sensitive coordination of support by an induction tutor. Again, however, little is known beyond that. What are the different contexts and discourses of lesson observation and feedback that are actually employed by people? There is, of course, an implicit official model which emphasises a structured approach, agreed agenda and time, and so on. There is too an expectation that the relevant set of competences will be the focus for observation and discussion and, indeed, a number of sensible assumptions can be made. For example, the induction tutor should start to observe the new teacher's teaching by the end of the first month or so, and on a regular basis thereafter; competences relating to classroom teaching should be a reference point at some stage, probably well before the end of the induction period; discussion of the lesson should take place immediately afterwards or as soon as possible following time for reflection. It is officially argued that specific competence statements, like those in the SFR, should be used as performance indicators (SOEID, 1996) to direct self-evaluation. However, this practice tends to generate further atomisation as competence statements are extended in more detailed close focusing methods (Buchanan and Jackson, 1997).

There is another assumption, however, that this is the way to get at an understanding and evaluation of teaching, and that this way is largely unproblematic if there is systematic reference to the prescribed standard 
(agenda item 1). But none of this is grounded in research. It should, therefore, be the task of research to establish what the perceived and actual developmental benefits are to new teachers of a structured, tightly focused approach such as this. It should equally be its task to examine alternative approaches to observing new teachers and helping them to make sense of their teaching. This is an area of teacher education in which teacher educators in higher education would claim to have vast experience and expertise, and yet it is largely untapped as a resource in teacher induction. Personal experience of working with student teachers in this area, and acquaintance with the work of colleagues, suggests that there are other ways of supporting new teachers. One contrasting approach is to use an open, narrative approach. This is essentially a chronological account of lesson episodes with comments, concluding with an analysis covering, for example, good features, critical points, lesson flow and suggested areas for development. This may be a way of arriving at particular aspects of teaching on which to focus in subsequent lessons. However, there is alack of research and evidnce in this area as well. The main question is thus concerned with the kinds of information and insights that can be obtained from open as well as focused observation of new teachers and the ways in which the resulting feedback contributes to their learning and development.

\section{Non-formal learning by new teachers}

While lesson observation and feedback is put forward as a significant agenda item in itself, there is a need for further exploration of the fuller context of support in which beginning teachers experience their development. To limit it solely to lesson observation and feedback by colleagues is to privilege one formal route of support over a broader concept of professional growth. There is a wider range of informal situations and relational conditions (McNally et al, 1997; Oberski et al, 1999) in which new teachers experience the transition into teacherhood. This has been given even further emphasis by Coffield (2000) as a necessity, not only for the individuals themselves but for their organisations, and theorised by Eraut (2000) in his typology of non-formal learning.

The fundamental issue here is our understanding of how new teachers experience learning to teach. Does whatever model of induction is to be used reflect the whole spectrum of professional and personal learning? It may be that the communities and significant relationships in this process, particularly in the experiential dimension of this early professional learning, are not determined by an imposed support structure, however well intentioned that may be. The early development of the teacher is clearly not as smooth as present policy implies. (Tickle, 200a; McCrone, 2000). The transitions from student teacher through induction to post-induction are recognised, but need to be better understood if support is to be meaningful. Imposition of support through formal programmes and structures, which are not informed by a more comprehensive understanding of how new teachers learn to teach, may not be cost effective and may also obstruct the teacher growth and development they are intended to promote. This understanding would have to take account 
of the effect of different contexts and schools (Keay, 2001) and the diverse individualism of new teachers.

\section{The qualities of individual new teachers}

As indicated earlier, the importance of individualised support has found expression in policy. This principle appears to have found a strong welcome in practice by new teachers, but it is also consistent with the central importance in the literature of the individual narrative in beginning teaching (Farr Darling, 2001; Flores, 2001). Reid (2001) has argued in an ITE context that the individual student should be the major aspect of research and, if we view early teacher learning as a coherent developmental entity, then the same research emphasis applies to the induction period. It is increasingly clear (Stronach et al, 2002) that self and professional identity has a strong presence in early professional learning. The focus here on the early development of the teacher should not exclude the wider comparative question across other professional contexts.

However, there is more to 'individualism' than guiding each novice through a prescribed induction curriculum. Attending to individual needs must mean more than simply working on weaknesses deriving from that curriculum. Anyone who has worked with teachers, perhaps especially new teachers, cannot be but aware of the special qualities they have as individual persons, and which imbue their teaching. We cannot pretend that 'good' teachers are simply the product of our ITE programmes and induction curricula, however highly these may be praised. Nor do we need to believe that 'good teachers are born not made' in order to hold the position that personal characteristics contribute much to the development of teacher performance and the individual sense of professional identity. The words of children themselves, the immediate' consumers' of teaching, should be invoked in this respect. Their take on good teaching is in part defined by its identification of human qualities. The Hay McBer study (2000), for example, allows the words of children to tell us that 'a good teacher '.... is kind, is generous, keeps confidences, doesn't give up on you, stands up for you, tells the truth, is forgiving...' (p.1), all undeniably fine qualities and not in any list of competences.

The question is, therefore, about how we ensure that the personal qualities that many new teachers bring to teaching are not squeezed out by an impersonal expression of competences and other statutory requirements. This is echoed to an extent in Reid's (2001) conclusion that the issue is how we recognise the diversity of individuals and use it to enhance their preparation for teaching. Teachers inevitably bring something of themselves into their work. The 'competent' teacher often has attributes that are not readily amenable to expression in a precise, measurable sense. They are integral to the person who is the teacher, an intrinsic part of who that person is or has become. A teacher may 'demonstrate' a particular competence, but that does not mean that 'teacher' can be viewed as built up of the complete list of competences. Rather, each competence demonstrated can be seen as just one manifestation of the teacher as a whole, recognising that there may be an 
infinite number of other ways in which the teacher might express competence (Heidegger??).There is no need to suggest that these qualities can or ought to be separated out of the teacher as a social being into some set of discrete descriptions. More pertinently, we should not be surprised that new teachers, as emerging leaders of children, display some of the elusive qualities of leadership: courage, dignity, integrity, generosity of spirit, for example.

\section{A pupil perspective on induction}

As well as 'the people you work with', it is 'the children you teach' who are felt by new teachers to be the other important group in their experience of becoming a teacher (McNally, 1994). The experience of teaching children determines whether you are accepted as a teacher, directly by them and indirectly through the impression colleagues have of this defining relationship. These relationships with children can be seen as part of the mentoring process in that new teachers are inducted into the cultural life of the school as much through their contact with the children they teach as with any other group or individuals. In other words, learning to teach does involve children themselves as informal sources of learning and support. Of course classroom observation and feedback draws on pupil behaviour in situ. In that sense, account is taken of pupils; but part of the pupil perspective is unseen by colleagues. It is experienced in the unobserved interactions between the new teacher and the class and, moreover, it is the pupil perspective on the new teacher, not the reverse, which is needed.

It is also a truism that pupils talk about their teachers. Teachers may indeed be influenced in their judgement of another (new) teacher from what pupils say. It is doubtful, however, if there is any political or professional appetite to formalise this kind of 'evidence'. Yet children in school are the primary 'consumers' of teaching and their voice should be heard. How to go about this is evidently a sensitive area, but it is an an area that is missing from the visible map of knowledge that we gather of new teachers. What we do have is a fairly well established set of statements by children about what makes a good teacher (e.g. Hay McBer, 2000). These may well be known to new teachers (and would have to be part of any induction curriculum in any case). What we should also ask is what makes a good new teacher? There may well be differences of content and priority between perceptions of newness and experience. Perhaps it is enough at this stage to acknowledge that there is an inevitable informal impression of an implicit pupil view within teachers' professional judgements.

The language of children is of course different from the language of competences, but there are also some notable absences from official statements, e.g. 'a sense of humour', that appear in many accounts of children's views. It might be important for new teachers to understand what children mean by such expressions. As indicated above, children's lists also tend to reinforce the contribution of personal qualities to professional competence. At an individual level, the question for the new teacher is, in what ways am 'l' showing, or not showing, the qualities of a good teacher? So 
it could also be acknowledged that new teachers should be encouraged to gain a sense of their own teaching, as part of self-evaluation and gathering of 'evidence', from the pupils they teach. Gaining a pupil perspective on induction cannot be ignored because it is difficult; possible ways of accessing it need to be further explored.

\section{A key purpose for teaching}

A sense of purpose in what we do is of course always a concern. There are, however, a number of reasons why the purpose (or purposes) of teaching needs to be re-visited now. There is a widespread awareness that great change is taking place in society and that this has implications for the place of the school and the role of the teacher. Of particular importance in Scotland, in this respect, is the impact of 'new community schools', where the intention is to provide an integrated professional service to a local community on a single site.

In the general call for greater accountability across the professions through clearer statements of what their responsibilities are, we should also ask what the distinctive, defining characteristics of different professions are. What is the nature of teaching in particular, and what is its purpose, or changing purpose, in a new social context? The changing categorisations of professionalism for teachers, and for new teachers in particular, accompanied as it is with the proliferation of competences, tends to obscure any sense of a central, unifying purpose to which new entrants can philosophically attach themselves. This expression of purpose is surely something which new teachers deserve.

There is also something of an anomaly in the developing Scottish framework of continuing professional development. The first standard to be published was the standard for headship (SOEID, 1998b) which, though it displayed an admirable atomisation of how to run schools, nevertheless managed to provide also a brief encapsulation of 'the key purpose for headship'. There has been no such attempt to reach a matching statement for teaching itself. The neglect of this task would appear to reach further south as well. In the shift to a standard based on more specific statements by the teacher training agency (1998), Reid (2001) draws attention to the absence of the key characteristics of teaching, analysis of the primary tasks of teachers and definition of their primary function, as well as the personal qualities or values required for success. While the later Hay McBer study (2000) does offer a substantial basis for attending to this neglect, and the various statements of teaching standards in Scotland do address values, it is the capturing of a concise statement of purpose in teaching that is required.

The point of placing it on the research agenda is primarily to stimulate a necessary debate. Certainly, teaching is complex by nature and there are many different perspectives offering different emphases and contrasting futures. There is a traditional view of teaching as instruction and the passing on of knowledge. More recently, the importance of enabling children to be more independent learners, of the teacher as facilitator of learning, has 
become part of the teaching role. Currently, it is increasingly recognised that teachers have a major contribution to make as partners in the protection and welfare of children. Whatever the age of the learner, whatever the specialist area of the teacher, there is surely a fundamental obligation on the part of teachers to visualise and nurture growth and development in the broadest sense. This requires of teachers a degree of personal commitment and aptitude as educators in contributing to their school or learning community, and in taking responsibility for their own development and learning. Do such general aspirations apply across the full range of schooling? Could they serve as a unifying purpose for teaching? The point is that some such expression of the enduring and expanding essence of teaching should be at the heart of any standard for teachers.

\section{Concluding comments}

The above areas then constitute an agenda for understanding induction and taking it forward. They have been presented as an array of concepts and organised into a constructive, topical agenda which, it is argued, should add a more formative dimension to research and development. They offer the prospect of a practical theory since they have a conceptual connection to practice and have a currency in policy terms. Indeed some of the emerging weaknesses in implementation are due to the absence of fundamental features of the early learning experience in the implicit policy model. There are, therefore, grounds for optimism that policy might be strengthened through their inclusion. At the moment, it is not too late. The agenda also offers an opportunity to get things 'right at the start', both in terms of early policy intervention (while induction is still a live issue), and in terms of the first steps of development as a teacher. It has to be said that there are a number of other large issues which have been excluded, for example assessment, tracking, funding and training. It is not that these are regarded as less important or less problematic, but they do have technical and administrative aspects (and are of course inherently practical) which are outside the scope of this paper. The paper has also drawn from the well of existing literature but there is an extensive hinterland of related ideas, often in other fields. Cultural psychology, for example, offers us the reciprocity of the ontogenesis and sociogenesis of knowledge (Valsiner and van de Veer, 2000) as a plausible balance of learning for the new teacher. The shift from maximum social relatedness to greater independence, found in workplace learning (Billett, 2002), echoes the theory of relational conditions in earlier work (McNally et al, 1997) on the experiential learning of new teachers. Such ideas have the potential to inform a more comprehensive theorisation of induction. Of particular relevance, for example, in understanding and describing early professional learning in the context of teacher development is surely the five-stage 'novice to expert' model of Dreyfus and Dreyfus (1985). It is important that a wider ranging literature study stays on the agenda.

Of course others will arrive at a different policy agenda and set of priorities. Questions arising from the first evaluations create an ongoing agenda, For example, Harrison (2001) points to the apparent absence of deeper reflection 
by new teachers during induction. This may be a product of the research assumptions and techniques employed but it may be an ineluctable developmental stage for many. The very nature of learning to teach - of needing time to come to terms with a bewildering assortment of interactions and decisions, of coping with life and work transitions - offers a highly plausible explanation of an apparent lull in profound thinking. But it should not it be assumed that theory is inevitably seen as distant and pointless. Holligan (1997), for example, has found that theory is used intelligently by students and can be a positive influence on their professional development. The conceptual research agenda here is seen as sufficiently robust to accommodate specific emerging concerns. It is nevertheless limited in scope and does not, for example, include comparative study across other professions, though this would be an important contextualising reference. Studies of early development in other professions is, for example, an evident extension of the work proposed here, not only in finding common theoretical ground but also in rendering a clearer sense of becoming and being a teacher (or a doctor, nurse, engineer etc.) through understanding of distinctive, defining differences.

There is, however, one crucial point for inclusion in the agenda. Interviews have served well so far in uncovering large-scale features of the early learning experience of new teachers and indeed workplace learning generally, but further understanding of induction shall require a methodological shift, probably involving re-appraisal of relationships with practitioners (e.g. Day, 1998; Huberman, 1999)). Earlier preliminary theorising (McNally et al, 1997) concluded that progressive focussing was required. Eraut (2000) too has also concluded that more sustained contact is needed to elicit richer data and fuller understanding. There is clearly a case, therefore, for developing a sharper, focused method of exploration in areas where we have a fairly well established broad brush picture. Careful design of a strategy, which incorporates a sharper methodological edge, has therefore a permeating presence in the agenda.

\section{References}

Association of Teachers and Lecturers (2000) Induction: bridge or barrier? London: ATL

Barnett, R. (1994) The Limits of Competence Bucks: OUP

Barnett, R. (2000) Realising the university in an age of supercomplexity Bucks: OUP

Billet, S (2002) Coparticipation at work: Affordance and engagement. In T Fenwick (Ed.) New Understandings of Workplace Learning San Fransisco: Jossey-Bass Publishers (in press)

Brown, S., McNally, J. and Stronach, I. (1993) Getting It Together: Questions and Answers about Partnership and Mentoring Stirling University/SEED 
Bubb, S. (2000) The Statutory Induction Period: issues for newly qualified teachers and induction tutors Paper presented at the annual BERA Conference Cardiff

Bubb, S., Jones, K., Heilbronn, R. \& Totterdell, M. (2001) An Outline of England's Induction Policy and a Critical Review of Literature on its Early Implementation Paper presented at the annual BERA Conference Leeds

Buchanan, D. \& Jackson, S. (1997) Self-evaluation for teachers and student teachers: a framework for professional development London: Kogan Page

Coffield F. (ed.) (2000) The necessity of informal learning ESRC Report Bristol: The Policy Press

Day, C. (1998) The Role of Higher Education in Fostering Lifelong Learning Partnerships with Teachers, European Journal of Education, 33,4, 419-432

Department for Education and Employment (1999) Circular 5/99: The Induction Period for Newly Qualified Teachers London: DfEE.

Draper, J., Fraser, H., Raab, A. and Taylor, W. (1997) Probationers on Supply Edinburgh University/GTC Scotland)

Dreyfus, H.L. and Dreyfus, S.E. (1986) Mind over machine: The power of human intuition and expertise the era of the computer Oxford: Basil Blackwell

Eraut, M. (2000) Non-formal learning, implicit knowledge and tacit knowledge in professional work, in Coffield F. (ed.) The necessity of informal learning ESRC Report Bristol:The Policy Press

Fairley, J and Paterson, L. (1995) Scottish education and the new managerialism Scottish Educational Review 27,13-36

Farr Darling, L. (2001) Portfolio as Practice: The Narratives of Emerging Teachers Teaching and Teacher Education 17,1,107-121

Flores, M. A. (2001) Person and Context in Becoming a New Teacher Journal of Education for Teaching 27,2,135-148

Harrison, J. K. (2001) The Induction of Newly Qualified Teachers Journal of Education for Teaching 27,3, 277-279

Hartley, D. (1997) The New Managerialism in Education: a mission impossible? Cambridge Journal of Education 27,1, 47-57

Hay McBer Report (2000) A Model of Teacher Effectiveness www.dfee.gov.uk/teachingreforms/mcber

Holligan, C. (1997) Theory in Initial Teacher Education: Students' perceptions 
on its utility as a case study British Educational Research Journal 23,4 533551

Huberman, M. (1999) The Mind Is Its Own Place: The Influence of Sustained Interactivity with Practitioners on Educational Researchers Harvard Educational Review 69,3,289-319

Humes, W. (2001) Conditions for Professional Development Scottish Educational Review 33,1,6-17

Keay,J. K. (2001) Every School Makes You a Different Teacher Paper presented at the annual BERA Conference Leeds

McCroneReport (2000) A Teaching Profession for the $21^{\text {st }}$ century: The report of the Committee of Inquiry into professional conditions of service for teachers Edinburgh: SEED

McNally, J. (2001) The Induction of New Teachers in Scotland: A Report for the General Teaching Council for Scotland and the Scottish Executive Department Edinburgh: GTC Scotland

McNally, J. (2000) Emerging issues and ideas for induction Teaching Scotland Issue 2, February 2000 Edinburgh: GTC Scotland

McNally, J., Cope, P., Inglis, W. and Stronach, I. (1997) The Student Teacher In School: Conditions for Development Teaching and Teacher Education $13,5,485-498$

McNally, J., Cope P., Inglis W. and Stronach I. (1994) Current Realities in the Student Teaching Experience Teaching and Teacher Education 10,2,219230.

McNally, J. (1994) Students, Schools and a Matter of Mentors The International Journal of Educational Management $8,5,18-23$

Oberski, I., Ford, K., Higgins, S. \& Fisher P. (1999) The Importance of Relationships in Teacher Education Journal of Education for Teaching $25,2,135-150$

Quality Assurance Agency for Higher Education (2000) The Standard for Initial Teacher Education in Scotland:Benchmark Information Gloucester:QAA.

Reid, I. (2001) The neglect of the ITE student in the reform of ITE in England and Wales in the 1990s, in Reid, I. (ed.) Improving schools: the contribution of teacher education and training London: Universities Council for the Education of Teachers

Scottish Executive (2002) The Supply of Teachers, available http://www.scotland.gov.uk (accessed 25/4/2002) 
Scottish Executive (2001a) The Standard for Full Registration as a Teacher in Scotland Edinburgh: SEED/ GTCS

Scottish Office (1996) How good is our school? Self-evaluation using performance indicators Edinburgh: SEED Audit Unit

Scottish Office (1998b) The Standard for Headship in Scotland Edinburgh

SOEID (1998a) Guidelines for Initial Teacher Education Courses in Scotland Edinburgh, Scottish Executive

Sutherland Report (1997) Report 10: Teacher education and training: a study, in Higher Education in the learning society The National Committee of Inquiry into Higher Education, Higher Education Quality Council

Simco N. (1999) The Induction of New Teachers: Problem Solving for 70 years Paper presented at the annual BERA Conference, Sussex

Stronach, I., Corbin, B., McNamara, O, Stark, S., Warne, T. (2002) Towards an uncertain politics of professionalism: teacher and nurse identities in flux Journal of Educational Policy (forthcoming)

Stronach, I., Cope, P., Inglis, B. and McNally, J. (1994) The SOED

'Competence' Guidelines for initial teacher training: issues of control, performance and relevance Scottish Educational Review 26,2,118-133

TTA (1998) National Standards for Qualified Teacher Status London: Teacher Training Agency

Tickle, L. (2000a) Teacher Induction: The Way Ahead Bucks: OUP

Tickle, L. (2000b) Teacher probation resurrected: England 1999-2000 Journal of Education Policy 15,6,701-713

Valsiner, J. and van de Veer, R. (2000) The Social Mind: The construction of an idea Cambridge: CUP

\footnotetext{
i The Scottish Executive have always referred to specific statements of competence in the terms, 'competence' and 'competences' rather than the more commonly used 'competency' and 'competencies'

ii The Registrar of the GTCS frequently used this term at meetings

${ }^{\text {iii }}$ Simply meeting up and talking about their experiences in teaching with fellow new teachers as peers often seems to matter more than the actual content of meeting. This was stated in informal conversation with a national official and yet we do not officially admit this

${ }^{\text {iv }}$ This information was given in a project interview by a headteacher of a large city secondary school

${ }^{\mathrm{v}} \mathrm{ICT}$ is already used extensively for teacher development in Argyll and Bute, and in Northern Ireland
} 